\title{
Microstructural strength of four subtropical soils evaluated by rheometry: properties, difficulties and opportunities
}

\author{
Patricia Pértile* , Dörthe Holthusen, Paulo Ivonir Gubiani, José Miguel Reichert
}

Federal University of Santa Maria - Soils Dept. - Av. Roraima, 1000 - 97105-900 - Santa Maria, RS - Brazil. *Corresponding author <patricia_pertile@hotmail.com>

Edited by: Silvia del Carmen Imhoff

Received June 30, 2016

Accepted January 21, 2017

\begin{abstract}
The structural strength of soils has been extensively described by physical and mechanical properties evaluated on the mesoscale for different soils and management conditions. However, changes in the organization of the soil matrix at the microstructural level, which can be obtained by rheometry, are still seldom used in soil mechanics. Our aim was to use the amplitude sweep test, a rheometry technique, to investigate the microstructural strength of four subtropical soils (two Oxisols, an Ultisol and a Vertisol) and to discuss difficulties with respect to the samples, water content, soil density and vertical force. The various rheological properties which reveal the soil microstructural strength were determined: deformation at the end of the linear viscoelastic range, LVE range $\left(\gamma_{\text {LVE }}\right)$, shear stress at the end of the LVE range $\left(\tau_{\text {LVE }}\right)$, deformation at yield point, $Y P\left(\gamma_{Y P}\right)$, storage and loss moduli at $Y P\left(G^{\prime} G^{\prime \prime}{ }_{Y P}\right)$, maximum shear stress $\left(\tau_{\max }\right)$, and integral $z$. In general, soil elasticity $\left(\gamma_{\text {LVE }}\right.$ and $\left.\gamma_{Y P}\right)$ and microstructural strength $\left(\tau_{\text {LVE }}\right.$ and $\left.\tau_{\max }\right)$ were greater in the Oxisols and the Vertisol, which both possess high clay content, while the latter also contains expansive clay minerals. The lowest structural strength was observed in the Ultisol which had a high sand content. As rheological properties are related to soil properties such as particle size distribution and carbon content, they can be applied in the evaluation of the microstructural strength of clayey and sandy soils and allows for inferences regarding interparticle shear strength. However, the test is not applicable to very dry soil samples and sample preparations can affect the results. We suggest a number of approaches to find solutions for these difficulties/problems.
\end{abstract}

Keywords: soil mechanics, oscillatory shear, amplitude sweep test, soil structure

\section{Introduction}

The processes of deformation and flow of soil mass originate from microscopic or molecular interactions of the constituents (Ghezzehei and Or, 2001). Deformation of soils on the microscale (particle level) due to external mechanical stress is related to physicochemical properties, including particle arrangement and cohesion (Markgraf and Horn, 2009), which in turn depend on grain size distribution, shape and type of clay mineral, soil organic matter and water contents (Oades and Waters, 1991; Markgraf and Horn, 2009; Markgraf et al., 2012), as well as the concentration of salts and cations in the soil (Markgraf and Horn, 2009).

The more usual physical and mechanical properties measured on the mesoscale are not sufficient to explain the mechanical processes and forces between soil particles (Markgraf et al., 2006). The theory and application of soil micromechanics can be better handled with rheometry techniques, in which soils are defined as viscoelastic materials, since the change in structure involves simultaneous elastic and plastic deformation (Mitchell and Soga, 2005; Markgraf and Horn, 2009). However, still very little is known about the rheological properties of soils.

Rheometry is a well-established analysis technique applied to various viscoelastic materials (Mezger, 2014), and in the last decade, there have been substantial advances in the use of this methodology for physico- chemical and mechanical analyses of soils (Baumgarten et al., 2013). For example, rheometry has been applied to the investigation of mineral dispersions and soils /Ghezzehei and Or, 2001; Or and Ghezzehei, 2002; Czibulya et al., 2010) and also to studies of the effects of inorganic fertilizer and biochar amendment on soil microstructure (Holthusen et al., 2012b, c; Ajayi et al., 2016). Moreover, it has been applied to the study of non-structured soil samples (Markgraf et al., 2006; Baumgarten et al., 2013) and in soils whose natural structure has been preserved (Holthusen et al., 2012a, b).

These investigations have contributed to the understanding of the interaction processes on the particle-toparticle scale, mechanisms for aggregation, strengthening and microstructural stability of different soils, and have evaluated the effects of water content, texture, mineralogy, concentration of salts, organic matter content and soil fertility management on these processes (Markgraf et al., 2006; Markgraf and Horn, 2007; Pértile et al., 2016). However, hitherto, this methodology has rarely been applied to subtropical/south Brazilian soils (Markgraf et al., 2006; Markgraf and Horn, 2007; Pértile et al., 2016), although these soils are quite different from the relatively well investigated European (temperate) soils.

Thus, our aim in this study was to apply the amplitude sweep test, a rheometry technique, to evaluate a number of rheological (micromechanical) properties of subtropical soils and highlight the prospects and challenges of the methodology viz-a-viz an evaluation of soil 
structural strength. This study is motivated by the growing application of rheometry to soil research particularly within temperate regions.

\section{Materials and Methods}

\section{Oscillatory shear and amplitude sweep test}

Classical mechanics such as Newton's law of ideal fluid and Hooke's law of ideal elastic solids are the basis for rheometry (Mezger, 2014). However, most materials, like soil, do not behave as ideal systems, since they exhibit a more complex deformation behavior pattern, including both elasticity and plasticity (Ghezzehei and Or, 2001; Schramm, 2006). Under steady stresses, soil deformation can be described by Bingham's law of viscoplastic materials (see also Terzaghi's theory of deformation or precompression stress which maintains that a soil is stable until a certain critical stress is exceeded - the "yield stress" according to Bingham).

Based on the different proportions of elastic and plastic or viscous deformation and flow, rheometry is applied to the performing of various types of tests, such as rotation, creep, relaxation, and oscillatory. Oscillatory tests are used to examine all kinds of viscoelastic materials (Mezger, 2014), including soil (Ghezzehei and Or, 2001; Holthusen et al., 2010). The principles of this test can be explained with the help of a parallel plates model: a sample is placed between two plates, the lower plate being fixed while the upper plate is rotated in an oscillatory manner (Figure 1) (Mezger, 2014), i.e. the plate is shifted alternately to the right and the left, in a sinusoidal function of time with at first a small deflection angle $\left(\varphi,{ }^{\circ}\right)$, creating a laminar flow within theoretically infinitesimal thin layers (Schramm, 2006). Thus, the deflection of the upper plate follows a similar sinusoidal function, while the deflection of the lower plate is zero $(s=0)$, generating resistance stresses or deformations in the sample (Schramm, 2006; Holthusen et al., 2010).

In oscillatory tests, $\gamma$ is calculated as the ratio of the deflection distance $(\mathrm{s}, \mathrm{m})$ and the distance between the plates $(\mathrm{h}, \mathrm{m})$ (Eq. 1). In the case of parallel circular plates, as is commonly used, $\mathrm{s}$ is determined as the deflection at the outermost edge of the plate (Figure 1A). The shear stress $(\tau, \mathrm{Pa})$ results from the force required to generate a deformation $(\gamma, \%)$ along the shear surface (Holthusen et al., 2010).

$\gamma=\frac{s}{h} 100$

The amplitude sweep test, among the oscillatory tests, has been the most widely used in soil investigations, being characterized by a variable amplitude (of deformation or shear stress) at a constant frequency (Markgraf et al., 2006). Either $\tau$ is defined and the resulting $\gamma$ is measured or vice versa (Markgraf et al., 2006). The latter, called "controlled shear deformation - CSD" has generally been used to assess microstructural soil behav-

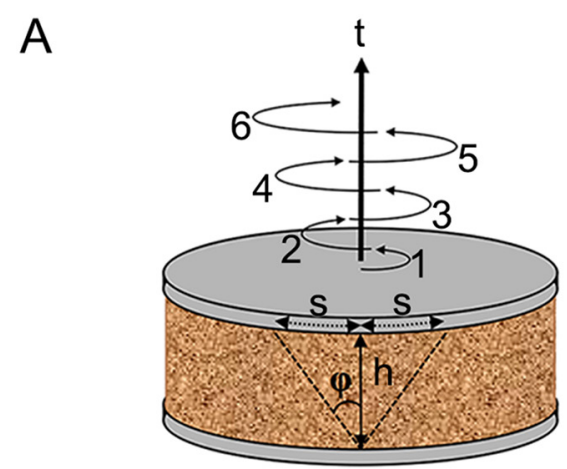

B

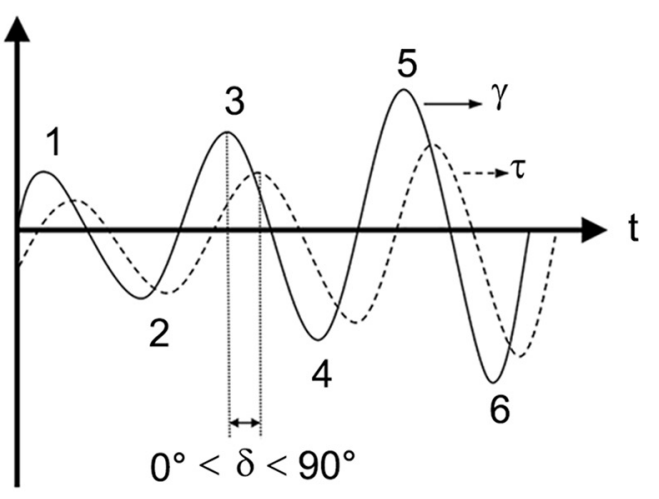

Figure 1 - Model of parallel plates in oscillatory shear tests ( $s=$ deflection distance, $\varphi=$ angle of deflection; $h$ = distance between plates) (A); and schematic results of an amplitude sweep test with increasing deformation $(\gamma)$ and shear stress $(\tau)$ as a function of time (t) (B). For viscoelastic substances, such as soil, the phase shift angle ( $\delta$ ) of $\tau$ from $\gamma$ is between 0 and $90^{\circ}$. Source: adapted from Mezger (2014).

ior (Markgraf et al., 2006). During an amplitude sweep test, the deformation amplitude increases over time, for example, between $0.0001 \%$ and $100 \%$ (Holthusen et al., 2010). Deformation of $100 \%$ occurs when deflection is equal to distance between the plates $(s=h)$ and, consequently, the deflection angle $\varphi$ equals $45^{\circ}$.

The relationship between controlled $\gamma$ and resulting $\tau$ is further described by the phase shift angle $\left(\delta,{ }^{\circ}\right)$ as characteristics of the soil (material) (Holthusen et al., 2010). Perfectly elastic substances react directly on the deformation, and therefore, $\tau$ and $\gamma$ curves are in phase, with $\delta=0^{\circ}$, while conversely, $\delta=90^{\circ}$ is characteristic of a perfect fluid. For viscoelastic substances, hence, $\tau$ shows a temporal lag with respect to $\gamma$ of the type $0<\delta$ $<90^{\circ}$ (Figure 1B) (Mezger, 2014).

\section{Determination of rheological properties}

To quantify rheological properties of viscoelastic materials by oscillatory shear tests, certain parameters have been adapted from classic mechanics. While, according to Hooke's law, the shear modulus $(G)$ under uniaxial stress conditions is constant for perfectly elastic substanc- 
es (Mezger, 2014); for oscillatory stresses a complex shear modulus $\left(G^{*}, \mathrm{~Pa}\right)$ is adapted (Eq. 2), which is divided into a storage modulus $\left(G^{\prime}, \mathrm{Pa}\right)\left(\right.$ Eq. 3) and a loss modulus $\left(G^{\prime \prime}\right.$, Pa) (Eq. 4) (Holthusen et al., 2010; Mezger, 2014).

$$
\begin{aligned}
& G^{*}=\tau_{\mathrm{A}} / \gamma_{A} \\
& G^{\prime}=G^{*} \cos \delta=\frac{\tau_{A}}{\gamma_{A}} \cos \delta \\
& G^{\prime \prime}=G^{*} \sin \delta=\frac{\tau_{A}}{\gamma_{A}} \sin \delta
\end{aligned}
$$

where $\tau_{A}$ is the amplitude of $\tau(\mathrm{Pa})$ and $\gamma_{A}$ is the amplitude of $\gamma(\%)$.

The storage modulus $G^{\prime}$ represents the elastic component of a material, indicating that part of the induced energy by the external stress is temporarily stored during the test to be retrieved upon the removal of stress. The loss modulus $G^{\prime \prime}$ is the viscous component or imaginary lost energy, which means that the energy used to initiate the flow is irreversibly lost (Markgraf et al., 2006; Schramm, 2006; Mezger, 2014). Both moduli $G^{\prime}$ and $G^{\prime \prime}$, depend directly on $\gamma, \tau$ and $\delta$ (Holthusen et al., 2010) recorded during the test.

The ratio of $G^{\prime \prime}$ and $G^{\prime}$ results in $\tan \delta$ (dimensionless) (Eq. 5), also referred to as loss factor, since it indicates the fraction of energy which is lost upon deformation (Horn and Peth, 2011). When $\tan \delta<1$ (G'> $G^{\prime \prime}$, the elastic component predominates; and when tan $\delta>1\left(G^{\prime}<G^{\prime \prime}\right)$, the viscous component is predominant (Markgraf et al., 2006). Thus, similar to $\delta, \tan \delta$ can be used to classify the mechanical strength of soil samples (Holthusen et al., 2010; Baumgarten et al., 2013).

$\tan \delta=\frac{G^{\prime \prime}}{G^{\prime}}$

For the curves of $G^{\prime}$ and $G^{\prime \prime}$ as a function of $\gamma$ (on a logarithmic scale), a linear viscoelastic range ( $L V E$ range) is determined, namely via the end of the LVE range at the limit of deformation $\left(\gamma_{L V E^{\prime}}\right.$ equal to $\gamma_{L}$ in some publications, \%) (Figure 2A) (Markgraf et al., 2006; Holthusen et al., 2010). The LVE range is defined as the range of deformation where $G^{*}$, consisting of $G^{\prime}$ and $G^{\prime \prime}$, is constant (Schramm, 2006); i.e. as long as the $\gamma_{L V E}$ is not exceeded no significant change in the soil internal structure occurs and deformation is reversible, while deformation beyond $\gamma_{L V E}$ causes irreversible changes in the sample, which is indicated by a decrease in $G^{\prime}$ and $G^{\prime \prime}$ (Holthusen et al., 2010; Mezger, 2014).

From the curves of $G^{\prime}$ and $G^{\prime \prime}$ versus $\gamma$ also their point of intersection (crossover or yield point - $Y P$ ) is obtained where $\tan \delta=1$ and $G^{\prime}=G^{\prime \prime}\left(G^{\prime} G_{Y P^{\prime}}^{\prime \prime} P a\right)$; i.e. the elastic and viscous components are equal (Figure 2A) (Holthusen et al., 2010). This point occurs already in the non-linear deformation range (Mezger, 2014) and is the critical deformation $\left(\gamma_{Y P}, \%\right)$ in which the viscous component exceeds the elastic and the sample flows, irreversibly modifying the particle arrangement (Markgraf et al., 2006; Schramm, 2006; Mezger, 2014).
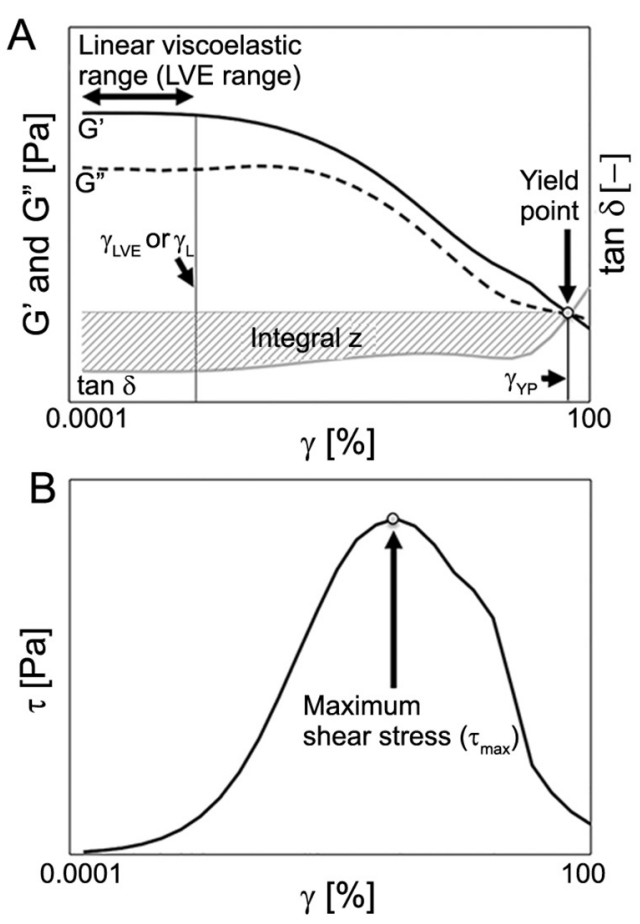

Figure 2 - Schematic results of an amplitude sweep test: storage modulus $\left(G^{\prime}\right)$, loss modulus $\left(G^{\prime \prime}\right)$ and loss factor $(\tan \delta)$ as a function of deformation $(\gamma)$, plotted on a logarithmic scale (A); and shear stress $(\tau)$ as a function of deformation $(\gamma)(B)$. Source: Pértile et al., 2016.

The integral $z$ and the maximum shear stress $\mid \tau_{\max }$ $\mathrm{Pa})$ have also been applied as rheological properties. The integral $z$ (dimensionless) is calculated as the area limited on the one hand by the curve of $\tan \delta$, from the lowest applied deformation (here $\gamma=0.0001 \%$ ) to the crossover, where $\tan \delta=1$, and on the other hand the line of $\tan \delta=1$ itself (Figure 2A). The greater the integral $z$ value, the higher the overall proportion of elastic deformation (as represented by $\mathrm{G}^{\prime}$ ), and therefore, the higher the rigidity of the soil (Markgraf et al., 2011). Additionally, $\tau_{\max }$ is the maximum $\tau$ shown by the sample during the amplitude sweep test (Figure 2B), indicating the maximum shear strength of a sample (Holthusen et al., 2012a). Further shear stress values used are $\tau$ corresponding to $\gamma_{L V E}$ and $\gamma_{Y P^{\prime}}$ respectively, $\tau_{L V E^{\prime}} \mathrm{Pa}$ (equal to yield stress $\tau_{y}$ in some publications) and $\tau_{Y P^{\prime}} \mathrm{Pa}$ (equal to flow stress $\tau_{f}$ (Mezger, 2014)).

The $\tau$ values are calculated from the recorded torque $(M, N m)$ necessary for the controlled deformation, and the plate radius $(r, m)$ (Eq. 6) (Mezger, 2014).

$\tau=\frac{2 M}{\pi r^{3}}$

This set of rheological properties $\left(\gamma_{L V E^{\prime}} \tau_{L V E^{\prime}} \gamma_{Y P^{\prime}}\right.$ $G^{\prime} G_{Y P \prime}^{\prime \prime} \tau_{\max }$ and integral $z$ ) provides key information about microstructural soil resistance (Markgraf et al., 2011). 
Table 1 - Description and characterization of the examined soils of Rio Grande do Sul, Brazil.

\begin{tabular}{|c|c|c|c|c|c|c|c|c|c|}
\hline Soila & Symbol & Geographic coordinates & Altitude & Sand & Silt & Clay & TC & CEC & $\rho_{B}$ \\
\hline & & & $\mathrm{m}$ & & $-g$ & $g^{-1}$ & - & $\mathrm{cmol}_{\mathrm{c}} \mathrm{kg}^{-1}$ & $\mathrm{~kg} \mathrm{~m}^{-3}$ \\
\hline Rhodic Kandiudox & Oxisol 1 & $28^{\circ} 38^{\prime} 17.83^{\prime \prime} \mathrm{S} ; 53^{\circ} 5^{\prime} 6.91^{\prime \prime} \mathrm{W}$ & 412 & 160 & 236 & 603 & 23.2 & 5.9 & 0.91 \\
\hline Typic Hapludox & Oxisol 2 & $28^{\circ} 30^{\prime} 38.09^{\prime \prime} \mathrm{S} ; 50^{\circ} 52^{\prime} 46.15^{\prime \prime} \mathrm{W}$ & 967 & 84 & 400 & 516 & 33.6 & 11.8 & 1.10 \\
\hline Arenic Hapludult & Ultisol & $30^{\circ} 41^{\prime 2} 25.23^{\prime \prime}$ S; 557'50.11" W & 165 & 844 & 98 & 57 & 6.2 & 2.2 & 1.66 \\
\hline Oxyaquic Hapluderts & Vertisol & $30^{\circ} 43^{\prime} 9.00^{\prime \prime}$ S; 5547'38.56" W & 233 & 87 & 476 & 437 & 44.1 & 43.0 & 0.94 \\
\hline
\end{tabular}

a Classification according to Soil Taxonomy (USDA, 2010); Sand, silt and clay = determined according to Suzuki et al. (2015), with sodium hydroxide (0xisols and Ultisol) and sodium hexametaphosphate (Vertisol) dispersant solution (Donagema et al., 2011); TC = total carbon, determined by dry combustion of soil macerated at autoanalyzer; CEC = cation exchange capacity, determined according to Donagema et al. (2011); $\rho_{\mathrm{B}}=$ bulk density, determined according to Blake and Hartge (1986) in samples obtained with preserved structure.
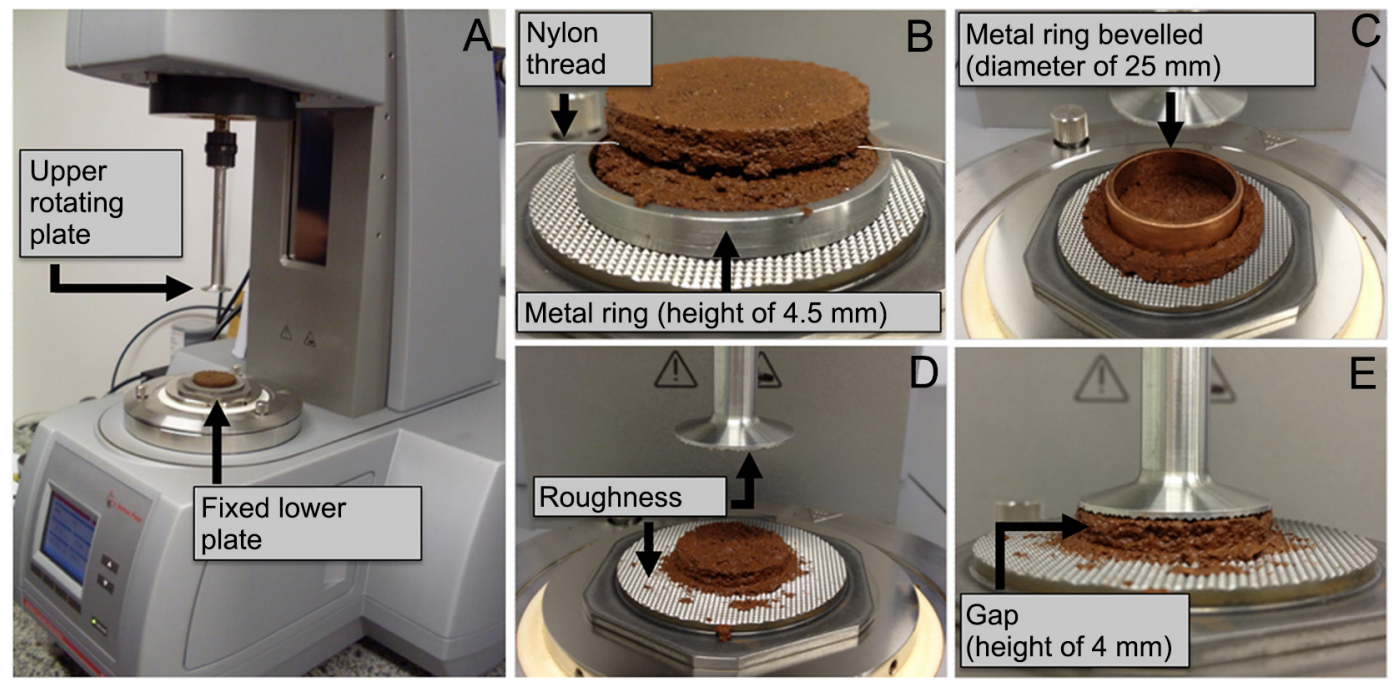

Figure 3 - Rheometer and measuring system of parallel plates (A). Soil sample preparation, consisting of: a horizontal cut (B), and a vertical cut (C); sample ready for the test after removal of excessive soil (D) and sample perfectly adjusted to the gap, i.e. the space between the plates (E).

\section{Soil analysis}

In order to conduct amplitude sweep tests, soil samples were collected from the superficial horizon of four soil classes of the state of Rio Grande do Sul (RS), southern Brazil (Table 1). These samples were collected from native forest - Rhodic Kandiudox (Oxisol 1), cultivated pasture - Typic Hapludox (Oxisol 2), and natural pasture - Arenic Hapludult (Ultisol) and Oxyaquic Hapluderts (Vertisol).

The soil samples collected were air-dried and sieved through a $2 \mathrm{~mm}$ mesh. In all the soil types, micro-aggregates were found, but those from Oxisol 2 and Vertisol were the most stable. The air-dried fine soil fraction $(<2 \mathrm{~mm})$ was slightly moistened and stored hermetically sealed for approximately $16 \mathrm{~h}$. The wet soil was then transferred to rings $(3.6 \mathrm{~cm}$ diameter and $1.0 \mathrm{~cm}$ height) and slightly compacted to a density equal to the average value of the soil bulk density $\left(\rho_{B}\right)$ in the field (Table 1). The samples (three samples by soil) were then saturated by capillarity rise with distilled water and subsequently drained to $-3 \mathrm{kPa}$ on sand columns (Reinert and Reichert, 2006).

Amplitude sweep tests at constant frequency and temperature were performed with a modular compact rheometer (MCR 102, Anton Paar, Germany) equipped with parallel plates: a fixed lower plate of $50 \mathrm{~mm}$ in diameter and an upper rotating plate of $25 \mathrm{~mm}$ in diameter, both roughened (Figures 3A, D) to optimize contact of soil and plate (MCR 102, PP25/P2 model, Anton Paar, Germany). From the repacked samples, a volume of approximately $4 \mathrm{~cm}^{3}$ was used in the rheometry tests. To ensure minimal disturbance, the samples were placed on the lower plate of the rheometer and gently pushed out of the rings. The samples were cut to a height of about $4.5 \mathrm{~mm}$ with nylon yarn and/or stiletto (Figure $3 \mathrm{~B}$ ) and vertically cut to size with a beveled ring of $25 \mathrm{~mm}$ diameter (Figure 3C) immediately before the test. The test samples were treated so as to exactly fit the diameter of the top plate and the gap (sample height) (Figures 3D, E), to avoid any possible effects of the surrounding soil (Holthusen et al., 2010) and ensure the equality of the initial conditions for all samples. To prevent loss of moisture, it was important that the samples were prepared as promptly as possible prior to measurement.

The amplitude sweep tests were performed under the following conditions: constant temperature of the lower parallel plate $=20{ }^{\circ} \mathrm{C}($ controlled by a 
Peltier unit); gap $=4 \mathrm{~mm}$ (Figure $3 \mathrm{E}$ ); resting period before the test $=30 \mathrm{~s}$; variation of amplitude of deformation $=0.0001$ to $100 \%$; angular frequency $=$ $0.5 \mathrm{~Hz}$; and number of measuring points $=30$ (according to Markgraf et al., 2006). Test duration was about $14 \mathrm{~min}$, which ensured minimal water loss from the sample during the test. The normal force on the sample did not exceed $12 \mathrm{~N}$ at the beginning of the test (Markgraf et al., 2006) (to obtain adequate sample-to-plate contact) and tended to $0 \mathrm{~N}$ in the end of the test.

Using the Rheoplus/32 V3.62 software program (Anton Paar, Germany) the rheological properties as described in the previous chapter were derived. The first three points of the 30 measuring points were excluded because of the lower sensitivity of the rheometer used (e.g. compared to a MCR 302, Anton Paar, Germany), when $\varphi<1$ rad. Samples with a water content loss of more than $10 \%$ were excluded due to the strong impact of water content on soil mechanics/ rheology.

\section{Results and Discussion}

\section{Rheological properties}

Soil rheological behavior was assessed from the curves of $G^{\prime}$ and $G^{\prime \prime}$ as a function of $\gamma$ (both in logarithmic scale) (Figure 4) and according to the properties derived from the amplitude sweep test results (Table 2). In the following discussion, we will follow an order in which the properties "appear" during the amplitude sweep test, starting with the initial values of $G^{\prime}$ and $G$ ". With increasing deformation, the nature of the properties is changing: While the LVE range properties are useful for describing "purely" elastic behavior (or fully recoverable deformation), the maximum shear strength

Table 2 - Mean values and standard deviation of rheological properties and gravimetric moisture $\left(\theta_{\mathrm{g}}\right)$ of soils $(\mathrm{N}=3)$ at matric potential of $-3 \mathrm{kPa}$.

\begin{tabular}{|c|c|c|c|c|c|c|c|}
\hline Soil & $\gamma_{L V E}$ & $\tau_{\text {LVE }}$ & $\gamma_{Y P}$ & $G^{\prime} G_{Y P}^{\prime \prime}$ & $\tau_{\max }$ & Integral z & $\theta_{\mathrm{g}}$ \\
\hline & $\%$ & $\mathrm{~Pa}$ & $\%$ & 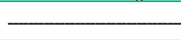 & 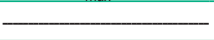 & - & $\mathrm{g} \mathrm{g}^{-1}$ \\
\hline Oxisol 1 & $0.009( \pm 0.001)$ & $116( \pm 12)$ & -a & $-\mathrm{a}$ & $1082( \pm 146)$ & $62( \pm 4)$ & $0.45( \pm 0.01)$ \\
\hline Oxisol 2 & $0.039( \pm 0.001)$ & $457( \pm 103)$ & $72( \pm 5)$ & $501( \pm 423)$ & $2702( \pm 718)$ & $34( \pm 6)$ & $0.51( \pm 0.00)$ \\
\hline Ultisol & $0.005( \pm 0.000)$ & $93( \pm 43)$ & $56( \pm 7)$ & $666( \pm 23)$ & $698( \pm 264)$ & $22( \pm 2)$ & $0.24( \pm 0.02)$ \\
\hline Vertisol & $0.045( \pm 0.001)$ & $171( \pm 12)$ & $62( \pm 4)$ & $656( \pm 109)$ & $1094( \pm 73)$ & $24( \pm 2)$ & $0.78( \pm 0.01)$ \\
\hline
\end{tabular}

$\gamma_{L V E}=$ deformation at the end of the linear viscoelastic range (LVE range); $\tau_{L V E}=$ shear stress at the end of $L V E$ range; $\gamma_{Y P}=$ deformation at yield point (YP); G'G" storage and loss moduli at $Y P ; \tau_{\max }=$ maximum shear stress; a No crossover detected.
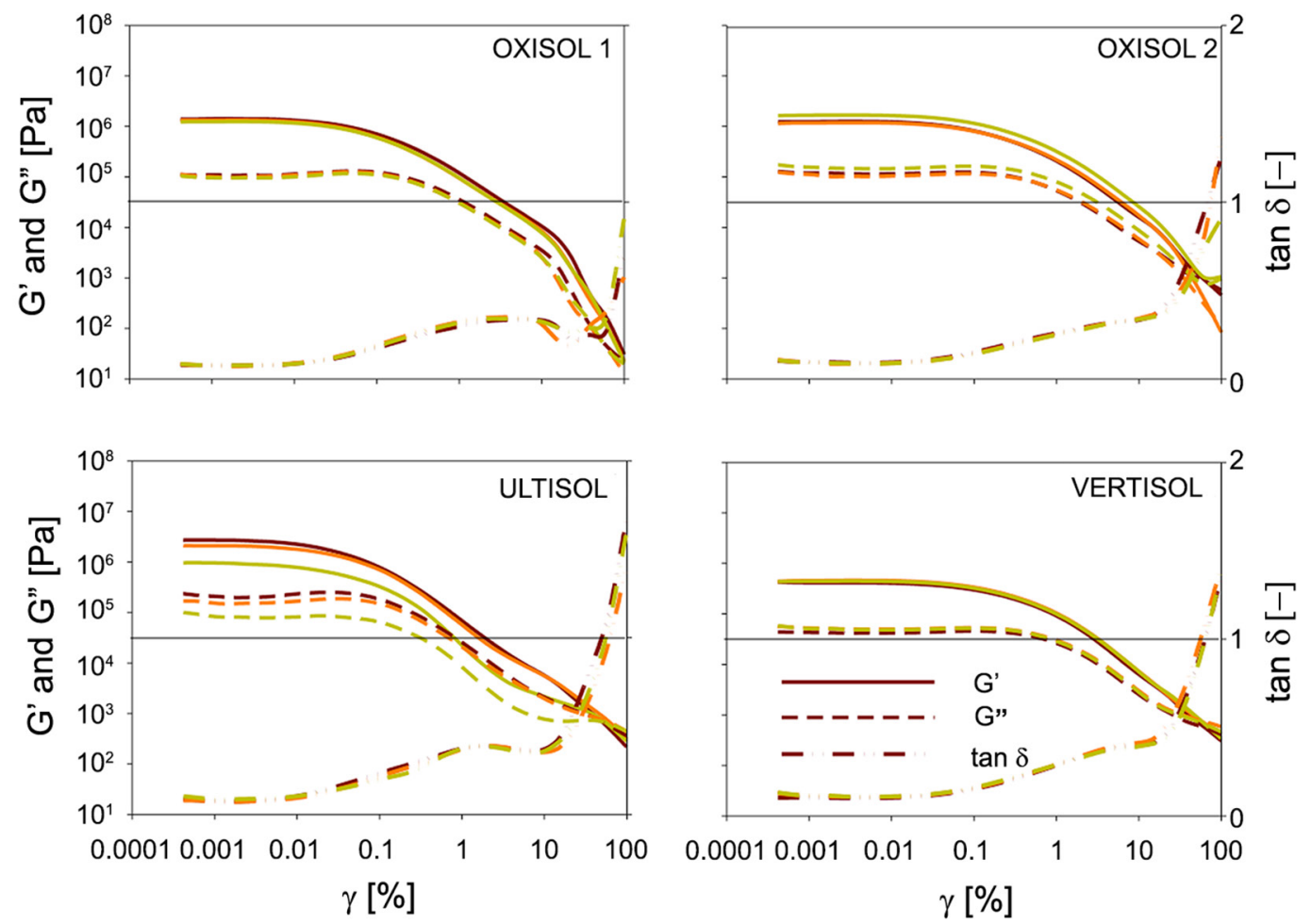

Figure 4 - Storage and loss modulus (respectivelly, $G^{\prime}$ and $G^{\prime \prime}$ ) and loss factor (tan $\delta$ ) versus deformation ( $\gamma$ ), on a logarithmic scale (pairs of lines correspond to repetitions), of soils at a matric potential of $-3 \mathrm{kPa}$. 
is independent of the concepts of elasticity or plasticity and denotes the shear resistance of the soil. The yield point is based upon the transition from mostly elastic $\left(G^{\prime}>G^{\prime \prime}\right)$ to mostly plastic behavior $\left(G^{\prime \prime}>G^{\prime}\right)$. In certain soils (as the Oxisol 1, see Table 2 and Figure 4), this transition is not achieved within the chosen range of the amplitude sweep test 0.0001 to $100 \%$ of deformation) (cf. Markgraf et al., 2011; Baumgarten et al., 2012; Pértile et al., 2016). As a consequence of their different characteristics and determination, the different rheological properties can indicate different directions of microstructural strength (stabilization vs. destabilization) within the same soil.

The initial values of $G^{\prime}$ and $G^{\prime \prime}$ differed between soils. For both Oxisols, the $G^{\prime}$ and $G^{\prime \prime}$ values were, respectively, $\approx 10^{6}$ and $\approx 10^{5} \mathrm{~Pa}$ (Figure 4). For the Ultisol these values were slightly higher, and for the Vertisol slightly lower, which is in agreement with the results of Markgraf et al. (2006). Higher values of $G^{\prime}$ and $G^{\prime \prime}$ indicate higher rigidity, which is related to the influence of texture, soil organic matter (SOM) and clay mineralogy (Markgraf and Horn, 2007), i.e. clay soils show higher structural rigidity than silty substrates (Markgraf and Horn, 2006a), as well as soils with higher contents of Fe oxides and SOM (Markgraf and Horn, 2007), since these factors promote favorable mechanisms for soil aggregation (Baumgarten and Horn, 2013).

The Ultisol was expected to exhibit the lowest values for $G^{\prime}$ and $G^{\prime \prime}$ as it has the lowest content of clay, organic matter and basic cations and is thus poorly aggregated. Therefore, it can be assumed that the high density of this soil increases its stability, especially as further properties denote low rigidity. The higher the density of a soil, the higher its shearing resistance and the lower the compressibility (Horn and Peth, 2011). The relatively higher initial values of $G^{\prime}$ and $G^{\prime \prime}$ for the Oxisols compared to the Vertisol are in accordance with the findings of Markgraf and Horn (2007) for samples drained to $-6 \mathrm{kPa}$. Markgraf and Horn (2006b) also measured higher initial values of $G^{\prime}$ and $G^{\prime \prime}$ due to low $\gamma$, i.e. the higher the $G^{\prime}$ and $G^{\prime \prime}$, the more stable the soil initially. However, there is not necessarily a direct relationship with the properties of the $L V E$ range. It is assumed that the wider the $L V E$ range (greater $\gamma_{L V E}$ ), the higher the elasticity of the soil, i.e. the recoverable deformation (Markgraf et al., 2006). The $L V E$ range was smaller for the Oxisol 1 and the Ultisol than for the Oxisol 2 and the Vertisol (Figure 4, Table 2). The higher values of $\gamma_{L V E}$ in the Vertisol probably derive from higher total carbon content (TC) as well as from high clay content and the presence of smectite. Carbon acts as a strong binding agent increasing soil stability (Six et al., 2004; Bronick and Lal, 2005; Kögel-Knabner et al., 2008; Holthusen et al., 2012a). This effect was confirmed by a decrease in $\gamma_{L V E}$ in soils subjected to oxidation of SOM to determine the stabilizing effect of SOM (Markgraf and Horn, 2007). Markgraf and Horn (2007), furthermore, observed a higher $\gamma_{L V E}$ in a Vertisol compared to different Oxisols. On the one hand, high clay and TC content in the Vertisol (Table 1) increased the elasticity due to adsorbed water, including (basic) cations in the soil solution and on the surfaces of the expansive clay mineral (smectite) (Markgraf et al., 2006). On the other hand, soils with higher kaolinite content and of coarse texture are less elastic (i.e. $\gamma_{L V E}$ is lower) (Markgraf and Horn, 2007), as is especially the case for the Oxisol 1 and the Ultisol (Tables 1 and 2). While in the Ultisol sandy texture and poor aggregation are supposedly the reason for the overall low stability and elasticity, in the Oxisols the existence of pseudosand seems to play a fundamental role. Both Oxisols exhibit pseudosand - stable microaggregates of sand diameter, but those in the Oxisol 2 are larger and more stable due to a higher abundance of goethite (yellow-brownish color), while the Oxisol 1 is dominated by hematite (red color) (data not shown). Only in the Oxisol 1, did the aggregation due to oxides (pseudosand) present a high degree of similarity with the sandy Ultisol (regarding LVE range properties), while the stronger, more concentrated aggregated Oxisol 2 showed a broader LVE range and the highest corresponding shear resistance.

Further to the $L V E$ range, the Ultisol exhibited an apparent increase in $G^{\prime \prime}$ (Figure 4), i.e. there was a relative increase in plasticity. The $\tan \delta$ curve, including similar information about the deformation behavior during the oscillatory shear, also showed a more pronounced increase in $\tan \delta$ between $\gamma$ of 0.01 and $10 \%$, followed by a decrease in the Oxisol 1 and the Ultisol (Figure 4). In both cases, this behavior is due to the reorientation of soil particles such as kaolinite platelets, individual packages or grains (Markgraf and Horn, 2007), which was not observed in the Vertisol and was less expressive in Oxisol 2, both with higher clay contents (Table 1). After the particles align, elasticity $\left(G^{\prime}\right)$ is increased relative to plasticity $\left(G^{\prime \prime}\right)$ again (Markgraf et al., 2006). This behavior was observed in the Oxisol 1, clayey and aggregated, possibly due to low $\rho_{\mathrm{B}}$ and presence of pseudosand and in the Ultisol due to high sand content (Table 1), which might cause dilatancy, i.e. an increase in shear resistance due to friction and restricted rotation of the sand and sand-like aggregates. Similarly, Markgraf et al. $(2006$, 2011) and Markgraf and Horn $(2006 a, 2007)$ observed this behavior in sandy and silty substrates, kaolinitic clay soils and soils with presence of pseudosand due to extreme shear strength (larger angle of internal friction).

The yield point, which indicates the transition from (mainly) elastic to (mainly) viscous deformation, occurred at relatively high deformations $\gamma_{Y P}$ (Figure 4). The largest values for $\gamma_{Y P}$ were observed in the Oxisol 1 ( $>100 \%$, no yield point, i.e. very high stability, no gelcharacter is reached), followed by the Oxisol $2(72 \%)$, the Vertisol (62\%), and the Ultisol (56\%) (Table 2). This result seems related to higher Fe oxides content of Oxisols 1 and 2 (data not shown), which are strong cementing agents (Six et al., 2004; Bronick and Lal, 2005). Although we also expected a greater influence of TC 
content on $\gamma_{Y P}$ (Baumgarten et al., 2013), this was not seen clearly. Soils with higher cation exchange capacity, soil carbon and $\mathrm{Ca}^{2+}$ content can be deformed to a greater extent before flow, i.e. possess a higher $\gamma_{Y P}$ (Markgraf et al., 2011), but according to Markgraf and Horn (2007) Fe oxides have a more stabilizing effect on the microstructural stability than, for example, the TC content.

In addition to the Fe oxides, the $\gamma_{Y P}$ is influenced by soil texture. For the Ultisol with loamy sand texture and low water content at $-3 \mathrm{kPa}$ (Table 2), the $\gamma_{Y P}$ was lower than for the more clayey Oxisol 2, and the Vertisol (Table 1), which had higher elasticity. Markgraf and Horn (2006a) also observed lower $\gamma_{Y P}$ in a sandy loam Haplic Chernozem compared to a silty loam Luvisol. The Oxisol 1 did not exhibit a yield point, which, as stated earlier, is indicative of a high degree of microstructural stability (Markgraf et al., 2011; Baumgarten et al., 2012). Markgraf and Horn (2007) also did not observe a yield point in clay-rich Oxisols, indicative of the very rigid character of these soils, as noted in the Oxisol 1 even with lower bulk density (less number of contact points between particles) than in the other soils (Table 1). Despite the low bulk density, the soil strength can be high due to an extremely stable arrangement of the soil particles and the cementation between particles (Dexter, 1988; Horn and Dexter, 1989) by clay minerals, oxides and inorganic and organic compounds (Dexter, 1988).

Integral $z$ was lower for Oxisol 2, Ultisol and Vertisol, and highest for the Oxisol 1 (Table 2). The high integral $z$ value, thus, confirms the greater structural rigidity of the Oxisol 1. Although the shear stress properties and the $L V E$ range do not suggest a very elastic and stable microstructure of this soil, our results are supported by Baumgarten et al. (2013), who also found similar values for sandy to loamy soils developed from volcanic ash, while silty to clayey soils had integral $z$ values of 30 to 50 at $-6 \mathrm{kPa}$. Furthermore, the Vertisol has quite a high water content, and sheared during the amplitude sweep test possibly causing liquefaction, intensified by supposedly low conductivity (water pressure cannot regain equilibrium so fast), while in the other soils both the conductivity is higher and the water content lower.

The $\tau_{L V E^{\prime}} \tau_{\max }$ and $G^{\prime} G^{\prime \prime}{ }_{Y P}$ are also useful properties for the rheological characterization of the soils. The $\tau_{L V E}$ and $\tau_{\max }$ were lowest for the Ultisol (Table 2), the sandiest soil (Table 1) and $G^{\prime} G^{\prime \prime}{ }_{Y P}$ was similar between soils, considering the high standard deviation values. The $\tau_{\max }$ indicates the maximum soil shear strength (Holthusen et al., 2012b), which was greater for the clayey soils in this study. Soil shear strength may also increase with increasing $\rho_{B}$ (Holthusen et al., 2012a), but for our soils, $\tau_{\max }$ and $\tau_{L V E}$ increased with clay content even with very low $\rho_{B}$ values (especially, Oxisol 1 and Vertisol) (Table 1). Thus, the Oxisol 2, clayey and with comparatively highest bulk density (1.10 $\mathrm{kg} \mathrm{m}^{-3}$, Table 1$)$ had the highest $\tau_{L V E}$ and $\tau_{\max }$. Therefore, soil composition appears to be more important than bulk density for shear strength of the soil, in agreement with Czibulya et al. (2010).
Furthermore, in direct comparison with the Oxisols, the different results for the different rheological properties indicate diverse types of aggregation and/or bonds between particles: the Oxisol 1 showed elasticity over a large range of deformations by means of integral $z$, but for others properties behave like a sandy soil despite a very high clay content of $603 \mathrm{~g} \mathrm{~kg}^{-1}$, due to the presence of microaggregates (pseudosand). It is possible that lower stability of these microaggregates enabled the particles to rearrange at higher deformation levels in stable arrangements of high friction. The Oxisol 2, on the other hand, with continuous increases in microaggregate stability compared to the Oxisol 1 (as proven by haptic test), had the highest friction and cohesion (as seen by shear stress properties $\tau_{L V E}$ and $\tau_{\max }$ ), though the bonds were lacking in elasticity, i.e. once they are destroyed, the soil does not regain its structure under the impact of transient stresses as it does during an amplitude sweep test (little thixotropy).

Thus, the results of the amplitude sweep test confirm previous research (Markgraf et al., 2006; Markgraf and Horn, 2007; Markgraf et al., 2011; Holthusen et al., 2012a, c; Baumgarten et al., 2013; Pértile et al., 2016) in proving that rheological properties are influenced by soil texture, mineralogy and carbon content.

\section{Difficulties and opportunities}

In general, rheological properties are obtained from materials/dispersions with a high water content. If the soil water content is low, the sample cannot deform homogeneously, which decreases the accuracy of rheological properties (Mezger, 2014). Therefore, samples are commonly drained up to - 1 to $-6 \mathrm{kPa}$. In some cases, -15 $\mathrm{kPa}$ was applied (Markgraf et al., 2011). Consequently, the use of rheological properties to predict soil deformation in the field is limited to the moisture range from saturation to around -6 or $-10 \mathrm{kPa}$. In the field, most soil tillage and crop management practices are carried out when the soil water content is lower (below field capacity) than that used in rheometry. Thus, soil deformation caused by machinery traffic with low water content in the soil may not be fully explained by the rheological properties, since as long as the dynamic forces are relatively small, the static stress strain processes may dominate the whole procedure. However, rheometry can be very important in situations such as landslides on slopes where low magnitude stresses cause devastating events during rainstorms (Horn and Peth, 2011).

Moreover, the soil structure was not preserved in our samples and nor were those of other investigations prepared for rheometry. To overcome this particular problem, recent studies are using samples with preserved structures (Holthusen et al., 2012a, b), which would provide the most representative rheological properties of the microstructure resistance of field soil. However, a further problem has to be solved: in samples with preserved structures, the spatial distribution of particles and microaggregates is not homogeneous, 
and plant root can be present. These factors might promote heterogeneous soil deformation during amplitude sweep tests and increase the variation in rheological properties between repetitions in the same soil. In addition, changes in density is likely to affect rheological behavior patterns. Thus, further studies are needed to validate the use of samples with preserved structures land those of different density due to structural distribution).

Moreover, rheometry studies generally use homogeneous soil samples and establish the same $\rho_{B}$ value for different soils, which is an advantage due to reducing independent variables which influence the rheological properties. However, the $\rho_{B}$ varies with soil composition, genesis and management (factors considered in preparing the samples of this study) and, in this case, the preparation of samples with the same $\rho_{B}$ does not represent the density condition in the field. Thus, studies are needed to determine the influence of $\rho_{B}$ on the rheological properties of different soils.

In the amplitude sweep tests, there is also great influence of normal stress $(\sigma)$ on rheological properties (Buchmann et al., 2015). We observed responsive increases in initial moduli $G^{\prime}$ and $G^{\prime \prime}$ caused by an increase of the $\sigma$, as annotated by an increase in the initial normal stress $\left(\sigma_{i}\right)$; (because the MCR 102 rheometer is not able to record the $\sigma$ during testing, the $\sigma_{i}$ is manually annotated). In the amplitude sweep test, the gap is kept constant, but the $\sigma_{i}$ cannot be fixed, it is only kept at less than $12 \mathrm{~N}$ (Markgraf et al., 2006) with the sample preparation. Even with the careful preparation of samples it is difficult to maintain the same value of $\sigma_{i}$ in all tests, because $\sigma_{i}$ varies with particle size, density, water content of the soil, and small variations in sample height. However, if $\sigma$ is kept constant during the test (in this case, the gap is not constant), changes in rheological properties due to a different $\sigma$ would be controlled. Control of the $\sigma$ in amplitude sweep tests is possible up to a maximum of $50 \mathrm{~N}$ (limited by the rheometer) and resembles more of the stresses imposed on the soil, for example, by the passage of agricultural machinery and animals, but this new technique requires new studies.

Furthermore, a note on nomenclature of rheological properties may be made in order to assist readers. According to Mezger (2014), the end of the LVE range is defined as a 'yield point' (from which significant change in the internal structure of the material starts to occur), while the point at cross over $\left(G^{\prime}=G^{\prime \prime}\right)$ is referred to as a 'flow point' (solid state changes to liquid state). However, it is possible to denominate the point at cross over as 'yield point - YP' (Mezger, 2014) (resulting in properties as $\gamma_{Y P}$ and $G^{\prime} G^{\prime \prime}{ }_{Y P}$ ), which is the nomenclature used in most studies on soil rheometry. Because of this, it is important that the nomenclature and obtaining of rheological properties are always well defined in publications to avoid mistakes in interpretation.

\section{Conclusions}

In general, as interpreted from our results, an increase in rheological properties represents increased soil microstructure resistance, but these rheological properties seem to be affected by different soil properties. Soil microstructural strength was greater in soils with higher clay and oxides content, and elasticity was greater in soils with higher clay content and expansive clay, while sandy soil (both naturally and by aggregation, "ecologically sandy") showed lower elasticity and sandy soil (naturally) showed lower structural strength. However, these relations have been little investigated; thus, it should be further elucidated which soil physical and chemical properties influence each rheological property and in what way.

Thus, the amplitude sweep test (rheometry) for mechanical evaluation in the soil particle scale and microaggregates is a modern technique that is already well established. However, this test is restricted to high matric potentials (i.e. saturation to approximate field capacity), hindering its application for the evaluation of soil deformation caused by machinery in ideal traffic conditions (low water content). Furthermore, we must be attentive to factors that affect the rheological properties such as the soil density of the prepared samples, the use of undisturbed soil samples, and normal stress before and/or during the test. For a better understanding of these factors, we suggest additional studies with undisturbed soil samples and homogenized soil samples of different densities. Further work is also required on the use of rheometry as a tool for the assessment of soil deformation under conditions of high soil water content, such as in areas prone to erosion and landslide.

\section{References}

Ajayi, A.E.; Holthusen, D.; Horn, R. 2016. Changes in microstructural behavior and hydraulic functions of biochar amended soils. Soil and Tillage Research 155: 166-175. doi:10.1016/j.still.2015.08.007

Baumgarten, W.; Dörner, J.; Horn, R. 2013. Microstructural development in volcanic ash soils from south Chile. Soil and Tillage Research 129: 48-60. doi:10.1016/j.still.2013.01.007

Baumgarten, W.; Neugebauer, T.; Fuchs, E.; Horn, R. 2012. Structural stability of Marshland soils of the riparian zone of the Tidal Elbe River. Soil and Tillage Research 125: 80-88. doi:10.1016/j.still.2012.06.002

Baumgarten, W.; Horn, R. 2013. Assessing soil degradation by using a scale-spanning soil mechanical approach: a review. p. 1-61. In: Krümmelbein, J.; Horn, R.; Pagliai, M., eds. Advances in geoEcology 42. Catena, Cremlingen, Germany.

Blake, G.R.; Hartge, K.H. 1986. Bulk density. p. 363-375. In: Klute, A., ed. Methods of soil analysis. Part 1. Physical and mineralogical methods. 2ed. American Society of Agronomy, Madison, WI, USA.

Bronick, C.J.; Lal, R. 2005. Soil structure and management: a review. Geoderma 124: 3-22. doi:10.1016/j.geoderma.2004.03.005 
Buchmann, C.; Bentz, J.; Schaumann, G.E. 2015. Intrinsic and model polymer hydrogel-induced soil structural stability of a silty sand soil as affected by soil moisture dynamics. Soil and Tillage Research 154: 22-33. doi:10.1016/j.still.2015.06.014

Czibulya, Z.; Tombácz, E.; Szegi, T.; Michéli, E.; Zsolnay, Á. 2010. Standard state of soil dispersions for rheological measurements. Applied Clay Science 48: 594-601. doi:10.1016/j. clay.2010.03.009

Donagema, G.K.; Campos, D.V.B.; Calderano, S.B.; Teixeira, W.G.; Viana, J.H.M. 2011. Manual of Soil Analysis Methods. = Manual de Métodos de Análise do Solo. 2ed. Embrapa Solos, Rio de Janeiro, RJ, Brazil (in Portuguese).

Dexter, A.R. 1988. Advances in characterization of soil structure. Soil and Tillage Research 11: 199-238. doi:10.1016/01671987(88)90002-5

Ghezzehei, T.A.; Or, D. 2001. Rheological properties of wet soils and clays under steady and oscillatory stresses. Soil Science Society of America Journal 65: 624-637. doi:10.2136/sssaj2001.653624x

Holthusen, D.; Peth, S.; Horn, R. 2010. Impact of potassium concentration and matric potential on soil stability derived from rheological parameters. Soil and Tillage Research 111: 75-85. doi:10.1016/j.still.2010.08.002

Holthusen, D.; Jänicke, M.; Peth, S.; Horn, R. 2012a. Physical properties of a Luvisol for different long-term fertilization treatments. II. Microscale behavior and its relation to the mesoscale. Journal of Plant Nutrition and Soil Science 175: 1423. doi:10.1002/jpln.201100076

Holthusen, D.; Reeb, D.; Horn, R. 2012b. Influence of potassium fertilization, water and salt stress, and their interference on rheological soil parameters in planted containers. Soil and Tillage Research 125: 72-79. doi:10.1016/j.still.2012.05.003

Holthusen, D.; Peth, S.; Horn, R.; Kühn, T. 2012c. Flow and deformation behavior at the microscale of soils from several long-term potassium fertilization trials in Germany. Journal of Plant Nutrition and Soil Science 175: 535-547. doi:10.1002/ jpln. 201100073

Horn, R.; Dexter, A.R. 1989. Dynamics of soil aggregation in an irrigated desert loess. Soil and Tillage Research 13: 253-266. doi:10.1016/0167-1987/89)90002-0

Horn, R.; Peth, S. 2011. Mechanics of unsaturated soils for agricultural applications. p. 3.1-3.30. In: Huang, P.M.; Li, Y.; Sumner, M.E., eds. Handbook of soil sciences. 2ed. CRC Press, Boca Raton, FL, USA.

Kögel-Knabner, I.; Guggenberger, G.; Kleber, M.; Kandeler, E.; Kalbitz, K.; Scheu, S.; Leinweber, P. 2008. Organo-mineral associations in temperate soils: integrating biology, mineralogy, and organic matter chemistry. Journal of Plant Nutrition and Soil Science 171: 61-82. doi:10.1002/jpln.200700048

Markgraf, W.; Horn, R.; Peth, S. 2006. An approach to rheometry in soil mechanics: structural changes in bentonite, clayey and silty soils. Soil and Tillage Research 91: 1-14. doi:10.1016/j. still.2006.01.007

Markgraf, W.; Horn, R. 2006a. Rheological strength analysis of $\mathrm{K}^{+}$-treated and of $\mathrm{CaCO}_{3}{ }_{3}^{-}$rich soils. Journal of Plant Nutrition and Soil Science 169: 411-419. doi:10.1002/jpln.200521934
Markgraf, W.; Horn, R. 2006b. Rheometry in soil mechanics: microstructural changes in a Calcaric Gleysol and a Dystric Planosol. Advances in GeoEcology 38: 47-58.

Markgraf, W.; Horn, R. 2007. Scanning electron microscopyenergy dispersive scan analyses and rheological investigations of South-Brazilian soils. Soil Science Society of America Journal 71: 851-859. doi:10.2136/sssaj2006.0231

Markgraf, W.; Horn, R. 2009. Rheological investigations in soil micro mechanics: measuring stiffness degradation and structural stability on a particle scale. p. 237-279. In: Gragg, L.P.; Cassell, J.M., eds. Progress in management engineering. Nova Science, New York, NY, USA.

Markgraf, W.; Watts, C.W.; Whalley, W.R.; Hrkac, T.; Horn, R. 2011. Influence of organic matter on rheological properties of soil. Applied Clay Science 64: 25-33. doi:10.1016/j. clay.2011.04.009

Markgraf, W.; Moreno, F.; Horn, R. 2012. Quantification of microstructural changes in Salorthidic Fluvaquents using rheological and particle charge techniques. Vadose Zone Journal 11: 1-11. doi:10.2136/vzj2011.0061

Mezger, T.G. 2014. The Rheology Handbook. 4ed. Vincentz Network, Hannover, Germany.

Mitchell, J.K.; Soga, K. 2005. Fundamentals of Soil Behavior. 3ed. John Wiley, Hoboken, NJ, USA.

Oades, J.M.; Waters, A.G. 1991. Aggregate hierarchy in soils. Soil Research 29: 815-828. doi:10.1071/SR9910815

Or, D.; Ghezzehei, T.A. 2002. Modeling post-tillage soil structural dynamics: a review. Soil and Tillage Research 64: 41-59. doi:10.1016/S0167-1987(01)00256-2

Pértile, P.; Reichert, J.M.; Gubiani, P.I.; Holthusen, D.; Costa, A. 2016. Rheological parameters as affected by water tension in subtropical soils. Revista Brasileira de Ciência do Solo 40: e0150286. doi:10.1590/18069657rbcs20150286

Reinert, D.J.; Reichert, J.M. 2006. Use of sand column to measure soil water retention: prototypes and test. Ciência Rural 36: 1931-1935. doi:10.1590/S0103-84782006000600044 (in Portuguese, with abstract in English).

Schramm, G. 2006. A Practical Approach to Rheology and Rheometry. 2ed. Gebrueder Haake GmbH, Karlsruhe, Germany.

Six, J.; Bossuyt, H.; Degryze, S.; Denef, K. 2004. A history of research on the link between (micro) aggregates, soil biota, and soil organic matter dynamics. Soil and Tillage Research 79: 7-31. doi:10.1016/j.still.2004.03.008

Suzuki, L.E.A.S.; Reichert, J.M.; Albuquerque, J.A.; Reinert, D.J.; Kaiser, D.R. 2015. Dispersion and flocculation of Vertisols, Alfisols and Oxisols in southern Brazil. Geoderma Regional 5: 64-70. doi:10.1016/j.geodrs.2015.03.005

United States Department of Agriculture [USDA]. 2010. Keys to Soil Taxonomy. 11ed. USDA-NRCS, Washington, DC, USA. 